\title{
Synthetic peptides mimicking antigenic epitope of Helicobacter pylori urease ${ }^{\star}$
}

\author{
Magdalena Białek ${ }^{1}$, Sebastian Grabowski², Zbigniew Kamiński ${ }^{1 \varpi}$ and Wiesław Kaca ${ }^{2,3}$ \\ ${ }^{1}$ Technical University, Department of Organic Chemistry, Łódź, Poland; ${ }^{2}$ Institute of Microbiology and Immu- \\ nology, University of Łódź, Łódź, Poland; ${ }^{3}$ Institute of Biology, Swietokrzyska Academy, Kielce, Poland; \\ 凶e-mail: kaminsz@mail.p.lodz.pl
}

Received: 06 November, 2005; revised: 26 January, 2006; accepted: 20 February, 2006 available on-line: 23 February, 2006

\begin{abstract}
Short peptides resembling the Helicobacter pylori urease antigen (UreB F8 Ser-Ile-Lys-Glu-AspVal-Gln-Phe) with deleted aspartic acid and glutamic acid residues, anchored through a triazine linker via the $\mathrm{N}$-terminal moiety to cellulose plate were prepared. The peptides were used for binding of antibodies from sera of patients with medically confirmed atherosclerosis. Recognition of the peptides was also tested with anti-Jack beans urease antibodies. The important role of a Gly-Gly spacer separating the peptides from the cellulose support was shown. Different patterns of binding of antibodies from $\mathrm{H}$. pylori infected patients and anti-Jack bean urease antibodies were observed only in the case of pentapeptides. The peptide Gly-Gly-Leu-Val-Phe-Lys-Thr was recognized by most of the tested sera.
\end{abstract}

Keywords: Helicobacter pylori, urease epitopes, synthetic peptides, atherosclerosis

The Gram-negative rod-like Helicobacter pylori is a major etiological agent of gastroduodenal ulcer diseases (Hirota et al., 2001). Helicobacter-induced gastritis is considered nowadays an epidemic, the prevalence of which is one of the highest world-wide (70\%). Possible links between $H$. pylori infections and human atherosclerosis have been suggested (Mendall, 1994). The etiology of atherosclerosis that may lead to coronary heart diseases (CHD) is multifactorial. Immunopathological processes such as molecular mimicry, epitope spreading, or bystander activation of self-reactive lymphocytes most likely fuel the chronic inflammatory process in the vascular wall (Ludewig et al., 2004). The prevalence and the levels of antibodies to H. pylori in the induction and maintenance of the diseases have been considered (Rechciński et al., 2005). Since urease is critical for virulence of $H$. pylori and, moreover, $H$. pylori urease has been suggested as a major immunodominant antigen detected in infected patients (Leal-Herrera et al., 1999), antibodies against this enzyme might be important in CHD.
It has been shown that $H$. pylori urease is build of two subunits - UreA (29.5 kDa) and UreB (66 kDa) (Hirota et al., 2001). UreB is the major target that is recognized by antibodies of $\mathrm{H}$. pylori-infected patients. The epitopes of monoclonal anti-urease antibodies L2 $(\mathrm{mAb})$ have been determined. The minimal epitope (F8) on the UreB was determined as the octapeptide Ser-Ile-Lys-Glu-Asp-Val-Gln-Phe (Hirota et al., 2001).

We synthesized a series of 20 peptides resembling the structure of F8 epitope. The aim of this studies was to find short synthetic peptides that bind effectively polyclonal antibodies from sera of atherosclerosis patients and IgG antibodies against Jack bean urease.

\section{MATERIALS AND METHODS}

All esters of amino acids were prepared according to a standard procedure of (Deffner et al.,

^Presented at the 18th Polish Peptide Symposium, 4-8 September, 2005, Wrocław, Poland.

Abbreviations: CDMT, 2-chloro-4,6-dimethoxy-1,3,5-triazine; CHD, coronary heart diseases; DCMT, 2,4-dichloro-6-methoxy-1,3,5-triazine; DMF, N,N-dimethylformamide; ${ }^{1} \mathrm{H}$ NMR, proton magnetic resonance; NMM, N-methylmorpholine; THF, tetrahydrofuran. 
1974). ${ }^{1} \mathrm{H}$ NMR spectra were measured on a Bruker Avance DPX-250 NMR spectrometer.

Immobilization of 2,4-dichloro-6-methoxy1,3,5-triazine on cellulose. Two sheets of Whatman filter paper $(5 \times 7.5 \mathrm{~cm})$ were treated with $1 \mathrm{M}$ $\mathrm{NaOH}(25 \mathrm{ml})$ for $15 \mathrm{~min}$ and drained. Then DCMT $(1 \mathrm{~g} ; 5.59 \mathrm{mmol})$ dissolved in acetone $(25 \mathrm{ml})$ and $\mathrm{NaHCO}_{3}$ (0.5 g; $5.95 \mathrm{mmol}$ ) was added and shaken for $50 \mathrm{~min}$.

The filter paper was washed with acetone until no reaction for DCMT was detected in the filtrate $(5 \times 25 \mathrm{ml})$ and dried in a vacuum desiccator.

Attachment of the first amino acid. The filter paper with immobilized DCMT was treated with a solution of the sodium salt of an amino acid $(1 \mathrm{mmol})$ in water $(2 \mathrm{ml})$ and left between glass plates in a closed vessel. After $24 \mathrm{~h}$ the filter paper was washed with water and treated with $1 \mathrm{M}$ aq. $\mathrm{NH}_{3}(25 \mathrm{ml})$ for $40 \mathrm{~min}$ to block unreacted triazine functional groups. The filter paper was again washed with water to neutralization and then treated with 1 $\mathrm{M} \mathrm{HCl}(25 \mathrm{ml})$ for $20 \mathrm{~min}$. Then it was washed with water until $\mathrm{pH}=7$, next once with acetone $(25 \mathrm{ml})$ for $5 \mathrm{~min}$ and dried in a vacuum desiccator.

Elongation of the peptide chain. Dried filter paper with attached amino acid or peptide was shaken for $2 \mathrm{~h}$ in a solution of NMM $(0.55 \mathrm{ml} ; 5$ mmol) in THF. Then it was washed with THF $(3 \times$ $25 \mathrm{ml}$ ) and dried. 2-Chloro-4,6-dimethoxy-1,3,5-triazine $(1 \mathrm{~g} ; 5.68 \mathrm{mmol})$ in THF $(25 \mathrm{ml})$ was added and the reaction was carried out for $4 \mathrm{~h}$. The excess of CDMT was washed off with THF $(5 \times 25 \mathrm{ml})$ and amino-acid methyl ester $(0.7 \mathrm{mmol})$ in DMF $(2 \mathrm{ml})$ with NMM (77 $\mu \mathrm{l} ; 0.7 \mathrm{mmol})$ was added. The filter paper was left between glass plates for $12 \mathrm{~h}$ and then washed with water/isopropyl alcohol solution $(1: 1)(3 \times 25 \mathrm{ml})$.

Deprotection of the carboxylic group. The filter paper with immobilized amino-acid methyl ester was shaken for $5 \mathrm{~h}$ in $1 \mathrm{M} \mathrm{NaOH}(25 \mathrm{ml})$, then was washed with water until $\mathrm{pH}=7$ and treated with 1 $\mathrm{M} \mathrm{HCl}(25 \mathrm{ml})$ for $25 \mathrm{~min}$. The filter paper was then washed with water to neutralization, washed with acetone and dried in a desiccator.

Developing reaction between peptides, patient sera and Jack bean urease-specific IgG antibodies - modified Western blot method. The filter paper (membrane) with attached peptides was divided into rectangles $0.25 \mathrm{~cm}^{2}$. Each rectangle was put into a well of immunological 24-well or 96-well plate and treated with buffer A (Tris/ $\mathrm{HCl}$, $\mathrm{pH}=7.45)$. In the next step buffer B $(10 \%$ fat-free instant milk dissolved in buffer A) was poured into the wells and the rectangles were left for $120 \mathrm{~min}$ on a shaker. After removing buffer B, patient sera or antibodies against Jack beans urease, diluted in buffer B (1:200) were added. The plate was locked tightly and incubated at room temp. on a shaker overnight. After removing the sera the rectangles were rinsed with buffer A six times on a shaker. After removing last drop of buffer $\mathrm{A}$ the rectangles were treated with class-specific (IgG) goat anti-human immunoglobulin coupled with horse radish peroxidase or goat anti-rabbit immunoglobulin (Sigma-Aldrich) coupled with alkaline phosphatase appropriately diluted (1:200) in buffer B and incubated for $120 \mathrm{~min}$ on a shaker. Then, the rectangles were again rinsed with buffer A six times on a shaker. Treatment with 4-chloro-1-naphtol (SigmaAldrich) developed blue-violet color of rectangles which bonded immunoglobulin.

As a positive and negative control of the reaction of antibodies, serum of one patient with medically confirmed $H$. pylori infection and one with no such an infection were used. The sera were a kind gift of Professor M. Chmiela (Institute of Microbiology and Immunology, University of Łódź, Poland).

Sera of 32 patients were purchased from the Department of Cardiology, Military Medical Hospital (Łódź, Poland). All patients were hospitalized for coronary artery by-pass graft. The experiments were performed according to Ethical Guidelines for Biomedical Research Involving Human Subjects.

\section{RESULTS AND DISCUSSION}

Short peptides resembling the F8 antigen, anchored via the $\mathrm{N}$-terminal moiety to cellulose, were prepared by multistep synthesis using CDMT as a coupling reagent (Kamiński, 1987).

The anchoring group was introduced by the treatment the cellulose with DCMT (Kamiński et al., 2000). Then, the first amino acid, in the form of its sodium salt, was attached to the triazine ring in a nucleophilic substitution reaction involving the amine group. In the next step the oligopeptide chain was synthesized by the stepwise elongation.

The carboxylic function of attached peptides was activated by treatment with CDMT in the presence of NMM, followed by coupling with aminoacid methyl esters and subsequent hydrolysis of protected carboxylic group.

Eleven peptides (1-11) were directly attached to the triazine ring. Four compounds $(12,13,14,15)$ were synthesized with using glycyl-glycine linker (Gly-Gly) and three compounds $(16,17,18)$ were synthesized using glycyl-glycyl-glycine linker (GlyGly-Gly) to step aside the oligopeptide even further from the cellulose support and to better expose the chain for the interaction with antibodies. In the case of two peptides $(19,20) \varepsilon$-amine in lysine residues remained protected with a benzyloxycarbonyl group. 

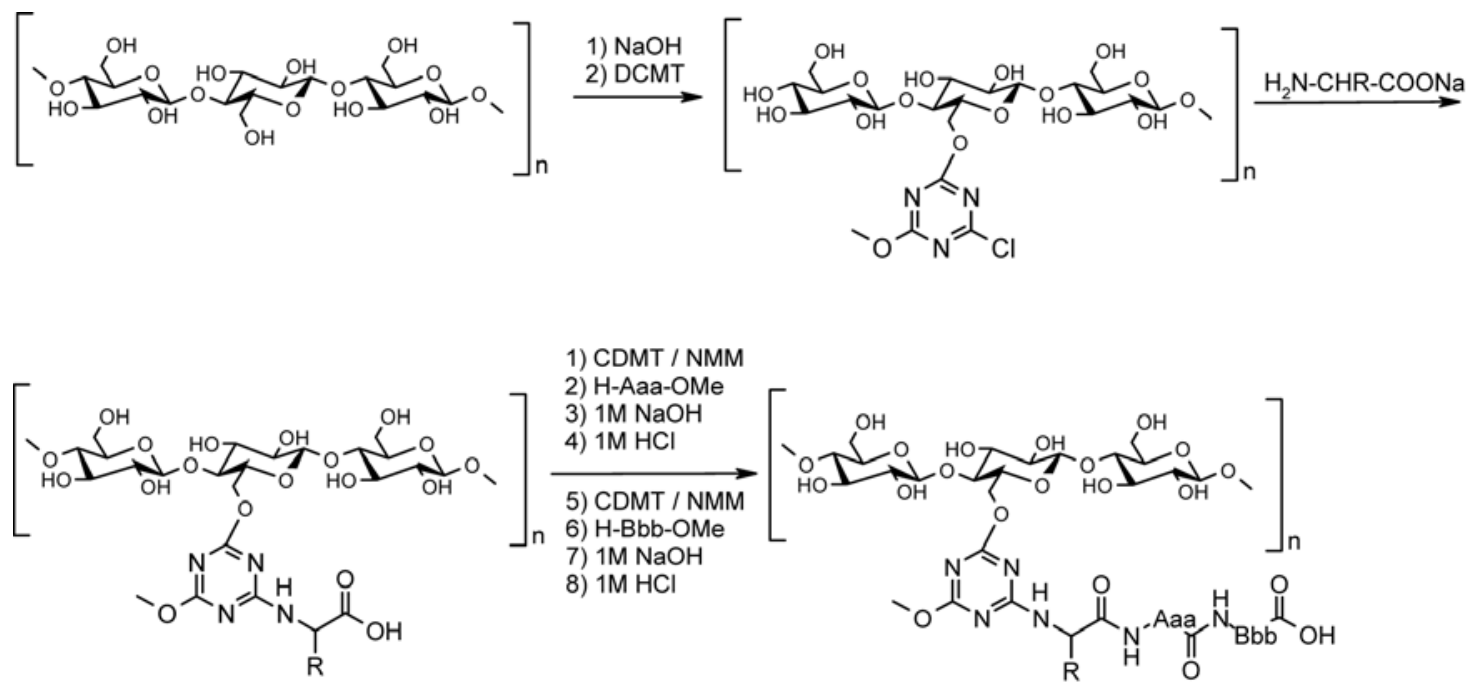

Figure 1. Synthesis of oligopeptides on cellulose using CDMT as a coupling reagent.

In all the analogues of F8 epitope the aspartic acid and glutamic acid residues were absent. We expected that due to the very dense population of the conformationally flexible oligopeptide chains covering the surface of the cellulose carrier, the C-terminal carboxylic groups of neighboring oligopeptide chains would mimic (Wucherpfennig, 2001) the carboxylic function of the side chains of both Asp and Glu residues.

Each compound was put to the positive control test with a patient's serum containing $H$. pylori anti-urease antibodies.
Thirty-two sera used in the experiments were from patients with medically confirmed atherosclerosis and after a coronary artery by-pass graft. All sera used in the reaction were tested with Jack bean urease for the presence of anti-urease antibodies. Although the Jack bean urease is only $70 \%$ compatible to $H$. pylori urease it is used in this type of studies with good results.

Twenty-six sera, from the total 32 used in this studies reacted with Jack bean urease, while six were negative (not shown).

Table 1. Synthesized oligopeptides and their interactions with sera

\begin{tabular}{|c|c|c|c|c|c|}
\hline Oligopeptides & $\begin{array}{l}\text { Positive } \\
\text { control with } \\
\text { patient's sera }^{\text {a) }}\end{array}$ & $\begin{array}{l}\text { Positive control } \\
\text { with anti-urease } \\
\text { antibodies }^{\text {b) }}\end{array}$ & $\begin{array}{l}\text { Positive intensive } \\
\text { results (no. of } \\
\text { experiments) }\end{array}$ & $\begin{array}{l}\text { Positive weak } \\
\text { results (no. of } \\
\text { experiments) }\end{array}$ & $\begin{array}{l}\text { Incon- } \\
\text { sistent } \\
\text { results }\end{array}$ \\
\hline 1. Ile-Lys-Val-Phe-Gly & - & + & $0(11)$ & $0(11)$ & 0 \\
\hline 2. Ser-Leu-Lys-Val-Phe & - & + & $4(32)$ & 3(32) & 0 \\
\hline 3. Leu-Val-Phe-Lys-Thr & + & - & $1(11)$ & $2(11)$ & 0 \\
\hline 4. Gly-Val-Lys-Tyr-Aib & + & + & $1(11)$ & $2(11)$ & 0 \\
\hline 5. Gly-Thr-Leu-Lys-Val & - & - & $2(11)$ & $1(11)$ & 1 \\
\hline 6. Gly-Leu-Lys-Val-Tyr & - & + & $1(11)$ & $0(11)$ & 1 \\
\hline 7. Ser-Val-His-Leu-Phe & + & + & $3(11)$ & $0(11)$ & 1 \\
\hline 8. Phe-Lys-Val-Leu-Thr & + & - & $2(11)$ & $3(11)$ & 1 \\
\hline 9. Phe-Val-Lys-Leu-Ser & + & nd & $2(32)$ & $1(32)$ & 0 \\
\hline 10. Val-Lys-Leu-Ser-Gly & + & nd & $4(32)$ & $2(32)$ & 2 \\
\hline 11. Leu-Lys-Val-Phe-Gly & + & nd & $7(32)$ & $2(32)$ & 4 \\
\hline 12. Gly-Gly-Ser-Leu-Lys-Val-Phe & + & + & $17(32)$ & $3(32)$ & 3 \\
\hline 13. Gly-Gly-Leu-Val-Phe-Lys-Thr & + & + & 18(32) & $11(32)$ & $\underline{3}$ \\
\hline 14. Gly-Gly-Phe-Val-Lys-Leu-Ser & + & + & $16(32)$ & $7(32)$ & 3 \\
\hline 15. Gly-Gly-Val-Lys-Leu-Ser-Gly & + & + & $9(32)$ & $11(32)$ & 4 \\
\hline 16. Gly-Gly-Gly-Ser-Leu-Lys-Val-Phe & + & + & $7(32)$ & $11(32)$ & 2 \\
\hline 17. Gly-Gly-Gly-Phe-Val-Lys-Leu-Ser & + & + & 6(32) & $5(32)$ & 2 \\
\hline 18. Gly-Gly-Gly-Val-Lys-Leu-Ser-Gly & + & + & $8(32)$ & $11(32)$ & 3 \\
\hline 19. Ile-Val-Phe-Lys(Z)-Thr & + & + & $6(32)$ & $16(32)$ & 5 \\
\hline 20. Gly-Thr-Leu-Lys(Z)-Val & + & + & $8(32)$ & $17(32)$ & 5 \\
\hline
\end{tabular}

nd, not determined; apositive control with anti-urease antibodies - control with one selected serum from the patient with medically confirmed H. pylori; bpositive control with anti-urease antibodies - control with anti-Jack bean urease antibodies; cinconsistent results - positive results with sera and negative control with anti-Jack bean urease antibodies. 
In a negative control test with patient's sera without anti-urease antibodies (H.pylori negative) no peptide (1-20) gave a positive immunological response.

Seventeen peptides were checked by commercially available anti-Jack bean urease antibody. In most of the cases the results were similar as with patient's sera. In two cases (2 and $\mathbf{6}-$ negative with patient's sera) the results were positives and the outcome of reaction with peptide $\mathbf{1 4}$ was rather weak positive.

We noticed that short oligopeptides (1-11) substantially less frequently gave positive results than oligopeptides with a linker (12-14, 15-18). The best results for an oligopeptide without a linker was given by compound 11. Nine sera gave a positive immune response, four sera gave inconsistent results. In the control test with anti-Jack bean urease six sera gave the negative result. This could be caused by the presence of other antibodies in the sera which could recognize the synthesized oligopeptides and subsequently be recognized by anti-human antibodies giving a positive response.

For peptides 19 and 20 (with protected $\varepsilon$-amino group in the lysine residue) 22 and 25 sera gave positive immune response respectively, although five sera gave inconsistent results.

Separating the peptides from the cellulose via glycine spacers increased their recognition by antibodies. In the case of peptide 2 (Ser-Leu-Lys-ValPhe) the diglycine linker increased the number of positive responses from 7 to 20 in 32 experiments, while with the triglycine spacer there were 18 positives responses. The best recognizable was peptide 13 with 18 very intensive and 11 weak responses (only three of them were inconsistent). However, a four-glycine spacer significantly reduced the reaction with the sera (compare peptides 12, 14 with $16,17)$.

It could be expected that recognition of short peptides with no glutamine, aspartic and glutamic acid residues is possible not as recognition of separate chains but rather of a $2 \mathrm{D}$ mosaic due to the dense population of flexible oligopeptides exposing carboxylic groups on the surface. It is also possible that the mechanism of the recognition is more complex because of the highly diversified repertoire of immune reactions designed to eradicate the rapidly changing pathogens (Farris et al., 2000). In this case, the diversity of the immune response may lead to potentially damaging self cross-reactivity which could be responsible for the pathogenic process of CHD.

\section{CONCLUSIONS}

The results obtained confirmed that in sera from CHD patients there are antibodies which recognize short peptides resembling the F8 epitope of H. pylori urease. The importance of a Gly-Gly spacer separating the peptides from the cellulose support was shown. Different patterns of binding of antibodies from H. pylori infected patients and of anti-Jack bean urease antibodies were observed only in the case of pentapeptides. The peptide sequence GlyGly-Leu-Val-Phe-Lys-Thr was recognized by most of the tested sera. The results will be used for designing a library of peptides useful for detection of antibodies specific for autoimmune diseases.

\section{Acknowledgement}

This study was supported by the State Committee for Scientific Research under the Project 4 T09A 18925.

\section{REFERENCES}

Deffbner M, Deimer KH, Jaeger E, Stelzel P, Thamm P, Wendlberger G, Wunsch E (1974) In Methoden der Organischen Chemie (Houben - Weyl), Synthese von Peptiden vol 15/1, pp 315-327, Georg Thieme Verlag, Stuttgart.

Farris AD, Keech CL, Gordon TP, McCluskey J (2000) Epitope mimics and determinant spreading: pathways to autoimmunity. Cell Mol Life Sci 57: 569-578.

Hirota K, Nagata K, Norose Y, Futagami S, Nakagawa Y, Senpuku H, Kobayashi F, Takahashi H (2001) Identification of an antigenic epitope in Helicobacter pylori urease that induces neutralizing antibody production. Infect Immun 69: 6597-6603.

Kamiński ZJ (1987) 2-Chloro-4,6-dimethoxy-1,3,5-triazine. A new coupling reagent for peptide synthesis. Synthesis 917-920.

Kamiński ZJ, Kolesińska B, Cierpucha M (2000) The method of manufacturing of coupling reagent immobilized on the solid matrix. Pat Appl no. P-338931 from 08. 03. 2000.

Leal-Herrera Y, Torres J, Perez G, Gomez A, Monath T, Tapia-Conyer R, Munoz O (1999) Serologic IgG response to urease in Helicobacter pylori-infected persons from Mexico. Am J Trop Med Hyg 60: 587-592.

Ludewig B, Krebs P, Scandella E (2004) Immunopathogenesis of atherosclerosis. J Leukocyte Biol 76: 300-306.

Mendall M (1994) Relation of Helicobacter pylori infection and coronary heart disease. Br Heart J 71: 437-439.

Rechciński T, Grębowska A, Kurpesa M, Rudnicka W, Krzemińska-Pakuła M, Chmiela M (2005) Occurrence of serum class $\mathrm{G}$ immunoglobulins interacting with specific antigens of Helicobacter pylori in patients with unstable coronary artery disease and in symptomless individuals. Pol J Microb 54: 221-225.

Wucherpfennig KW (2001) Structural basis of molecular mimicry. J Autoimm 16: 293-302. 